\title{
Effect of Ethanol Extract of Irvingia Gabonensis (Aubrey Lecomte Ex O. Rorke) Baill. (Irvingiaceae) Seeds on Diet Induced Obesity in Wistar Rats
}

\author{
'Temitayo 0. AJAYI', Adewale G. BAKRE', Toba C AKINTAYO², Oluwatomi 0. BAMIGBOYE' \\ 1 Department of Pharmacognosy Faculty of Pharmacy, University of Ibadan, Nigeria. \\ 2Department of Pharmacology and Toxicology, Faculty of Pharmacy University of Ibadan, Nigeria. \\ 3 Department of Physiology, College of Medicine and Health Sciences, Afe Babalola University Ado-Ekiti, Ekiti State, \\ Nigeria.
}

\begin{abstract}
Obesity is a chronic condition associated with high morbidity and mortality rates. Its comorbidities include cancer, diabetes mellitus, and cardiovascular diseases. Traditional medicines have found increasing use due to cost effectiveness and minimal side effects. This study evaluated the Anti-obesity effect of ethanolic extract of Irvingia gabonensis seeds.

Wistar rats were divided into control and treatment groups. Untreated group I on normal diet (negative control), untreated group II on high fat diet (HFD) and 10 $\mathrm{mL} / \mathrm{Kg}$ Tween 80 (positive control), extract treated groups III-V (50, 100 and 200 $\mathrm{mg} / \mathrm{Kg}$ ) on HFD. Orlistat treated group VI (200 mg/Kg) on HFD (standard). Body mass index (BMI), weight of abdominal fat, cholesterol levels and hepatic enzymes were evaluated after 12 days of treatment.

Body mass index (BMI) and abdominal fat of (treatment groups) reduced. However, the seed extract and orlistat did not significantly increase liver enzymes. Conclusion: Irvingia gabonensis seed extract showed anti-obesity properties.
\end{abstract}

Keywords: Obesity, Body mass index, lipid profile, Irvingia gabonensis ethanolic extract, High fat diet.

\footnotetext{
*Corresponding author:

Temitayo 0. Ajayi

Telephone: +2347030308600

E-mail: tayomiajayi@yahoo.com

ORCIDs:

Temitayo Ajayi: 0000-0003-0100-1083

Adewale Bakre: 0000-0001-9769-8510

Toba Akintayo: 0000-0003-1717-9214

Oluwatomi Bamigboye: 0000-0003-1649-7704

(Received 30.April 2020, accepted 10 February 2021)
} 


\section{INTRODUCTION}

Obesity is a pathological condition in which excess body fat is accumulated and resulting in adverse effects on health and life expectancy. It is a chronic disorder involving a complex interaction between genetic and environmental factors ${ }^{1}$. Obesity normally occurs when energy intake exceeds energy expenditure. It is a complex health issue resulting from a combination of causes and individual factors such as behavior and genetics. Behaviors can include physical activity, inactivity, dietary patterns, medication use, and other exposures. Additional contributing factors include the food and physical activity environment, education and skills, and food marketing and promotion. ${ }^{2}$

Medicinal plant preparations containing naturally active ingredients have been used either to enhance satiety or boost metabolism of high energy dense food to speed up weight loss ${ }^{3}$. Anti-obesity mechanisms for herbal plants included reduction in lipid absorption, reduced energy intake, increased energy expenditure, decreased pre-adipocyte differentiation and proliferation, or decreased lipogenesis and increased lipolysis ${ }^{4}$. Adipose tissue as an endocrine organ contributes in the mechanisms of obesity by secreting cytokines like interleukin 6 (IL-6) and Tumor necrosis factor alpha (TNFa): which therefore could regard obesity as a chronic inflammatory disease ${ }^{5}$. The physiological mechanism of high-fat diet induced obesity is related to the energy derived from fat which has a greater effect on body weight gain than the energy from non-fat diet ${ }^{6}$. Another mechanism involved in obesity is in hyperleptinemia and leptin resistance on high fat diet which involved the hypothalamic leptin receptors and signaling pathways ${ }^{7}$. Another contributory factor to obesity is stress; long term stress is associated with increase food intake and thus promotes fat and weight gain in human subjects ${ }^{8}$.

Currently, $80 \%$ of the world population use plant-derived drugs as the first-line in treatment of obesity because of their efficacy and minimally tolerable side effects ${ }^{9}$. Allium cepa (Onion; Family: Amaryllidaceae), Trigonella foenum-graecum (Fenugreek; Family: Fabaceae) Cyamopsis tetragonoloba (Guar; Family: Leguminoceae) and Hibiscus cannabinus (Kenaf; Family: Malvaceae) are examples of plants with proven antiobesity activity ${ }^{10}$. Some families of plants with anti-obesity effects include: Apocynaceae, Rutaceae, Leguminosae, Malvaceae, Moraceae, Compositae, Rubiaceae and Zingiberaceae ${ }^{11}$.

The Irvingiaceae family is a small woody family that consists of 10 species in three genera. The genera include Desbordesia Pierre ex Tiegh(one species), Klainedoxa Pierre ex Engl. (two species) and Irvingia Hook. f. (seven species) which are distributed in central and west Africa except Irvingia malayana Oliv., which is found in southeast Asia. The family was formerly placed in the 
Simaroubaceae family or as a distinct family in the Rutales. Later on, the Angiosperm Phylogeny group placed it in the Malpighiales on the basis of molecular evidence $^{8}$. To gain insight into family relationships, 63 embryological characters of two previously unstudied African species, Irvingia gabonensis and I. smithï, were investigated by Tobe and Raven in 2011 and were compared to other Malpighiales and the sister group Oxalidales. Embryologically, Irvingia was found to be characterized by the absence of an integumentary tapetum and by having a non-multiplicative inner integument, a multiplicative testa, many discrete fascicles of vascular bundles running in the testa from the raphe to antiraphe, and a fibrous exotegmen. Comparisons showed that Irvingia did not resemble any of the Linaceae, Caryocaraceae, Erythroxylaceae, Rhizophoraceae, or any of the other malpighialean families. The genus rather resembled Huaceae and Connaraceae (Oxalidales) in seed coat structure. It has been reported to have a number of beneficial medicinal effects such on gastrointestinal discomfort and diabetes ${ }^{12}$. It is also known to have analgesic and antioxidant properties ${ }^{13}$.

Irvingia gabonensis (gabonensis) (Aubrey Lecomte ex O. Rorke) Baill. is a sweet variety which is a large tree that grows up to 15-40 meters and a diameter of about $120 \mathrm{~cm}$. Its trunk is slightly buttressed; it has a dense, compact crown, branchlets ending in a narrow, curved, stipular sheath covering the leaf bud. Leaves are elliptic or slightly obovate, acute to acuminate and cuneate. They are 5-15x2.5-6 cm in size and usually have 5- 10 pairs of irregular lateral veins. The leaves are dark green in color and leathery and glossy. Flowers are yellow or greenish-white in color. They are slender; they have racemes which are slender or small panicles above the leaves or on the branches. Their flower stalk is slender and about $6 \mathrm{~mm}$ long. Fruits are yellow in color when ripe, broadly ellipsoid and are variable in size. They are $5-7.5 \mathrm{~cm}$ in size with a yellow, fibrous pulp surrounding its large seed ${ }^{14}$. The seed has medicinal, nutritional and industrial uses and very rich in fats, proteins and in lipids than other oil seeds and legumes such as groundnut, melon, soybeans and cotton seed. The seeds are a source of human food and constitute important part of the diet in most parts of Nigeria. The seeds are ground and used as thickening agents in soups. Other parts of the tree, like the bark and the leaves have been used in gastrointestinal conditions as laxatives and its oil processed into soap or pharmaceuticals ${ }^{15}$.

The nutritional analysis of I. gabonensis (gabonensis) shows that its seeds contain $3.36 \% \mathrm{~m}$ moisture, $7.70 \%$ crude protein, $65.46 \%$ crude fat, $2.26 \%$ mineral ash, $10.23 \%$ crude fiber and $10.93 \%$ carbohydrate. The pulp contains $80 \%$ moisture, $1.09 \%$ crude protein, $1.06 \%$ crude fat, $0.8 \%$ mineral ash, $0.4 \%$ crude fiber and $10.7 \%$ carbohydrate. The physicochemical evaluation of the pulp contains $0.21 \%$ water soluble ash, $459.7 \mathrm{mg} / 100 \mathrm{~mL}$ reducing sugars, $49.1 \%$ non- 
reducing sugars, $0.112 \mathrm{~cm}^{3}$ titratable acidity, 10.0 (Brix) soluble solids, $10.0 \%$ total solids, 1.012 specific gravity and 1.3355 refractive index ${ }^{16}$. The phytochemical analysis of the seeds of I. gabonensis (gabonensis) revealed the presence of alkaloids, flavonoids, tannin, volatile oils, saponins, terpenoids, carbohydrate and cardiac glycosides but no resins were found ${ }^{17}$.

Ethnopharmacology uses of I. gabonensis (gabonensis) include as antifertility, antimicrobial and antidiabetic agents. This in vivo study sought to compare the effect of Irvingia gabonensis seed and Orlistat (Reference standard) on diet induced obesity as can be adaptable in humans.

\section{METHODOLOGY}

\section{Experimental animals}

Male Wistar rats weighing ( $60-70 \mathrm{~g}$ ) were used in the study. They were purchased from the Central Animal House, University of Ibadan and housed in plastic cages at room temperature and had free access to rodent pellet diet and water ad libitum. The animals were allowed to acclimatize for one week before the experiment. All rats were handled in accordance with the National Institutes of Health (NIH) Guidelines for the Care and Use of Laboratory Animals and OECD guidelines for testing of chemicals (NIH publication \#85-23, 1985).

The experimental protocol was in conformity with the Ethics Committee Guidelines of the University of Ibadan with ethical approval number (UIACUREC/17/0105) as well as the US guidelines of internationally accepted principles for laboratory animal use and care.

\section{Plant materials}

Fresh seeds of Irvingia gabonensis (gabonensis) were obtained from the Bodija market, Ibadan, Oyo State, Nigeria. The seeds were authenticated by Mr. Adeyemo of the Forestry Research Institute of Nigeria, Ibadan with the voucher specimen number, FHI: 111042.

\section{Extraction}

The seeds of I. gabonensis (gabonensis) were broken into smaller pieces. They were then placed in an oven at a temperature of $36^{\circ} \mathrm{C}$ and $40^{\circ} \mathrm{C}$ to dry. After a few hours in the oven, a blender was used to grind the seed pieces to powder which was then poured into a macerating jar. The ethanol extract of I. gabonensis (gabonensis) was obtained by first defatting it in distilled $n$-hexane twice. The marc from the seeds was filtered and air- dried and was macerated in 70\% distilled ethanol at room temperature for $72 \mathrm{~h}$. The extract was filtered and concentrated using a rotary evaporator at $40^{\circ} \mathrm{C}$. 


\section{Experimental Design and Drug Treatment}

Thirty rats were randomly divided into six groups of five animals each $(n=5)$. Group I consisted of normal diet control rats (ND), group II consisted of the untreated high fat diet (HFD) fed rats treated with $10 \mathrm{~mL} / \mathrm{Kg}$ vehicle (Tween 80), groups III-V consisted of rats fed with high fat diet but treated with 50, 100 and $200 \mathrm{mg} / \mathrm{kg}$ ethanol extract of I. gabonensis (gabonensis) seed (EIGS). Group VI also consist of rats fed with high fat diet but treated with $200 \mathrm{mg} / \mathrm{kg}$ orlistat. The rats were fed till their BMI was above 310, for twelve days before treatment. Body mass index was calculated using the Lee's index formula:

$$
B M I=\frac{\sqrt[3]{\text { weight }}(\mathrm{g})}{\text { Length }(\mathrm{cm})} \times 1000
$$

The length was measured from the nose to the anus (naso-anal) for each animal after every 3 days during treatment. Animals were sacrificed $24 \mathrm{~h}$ after the last treatment. Abdominal fats and blood (through cac puncture) were collected for lipid profile and biochemical analysis.

\section{Biochemical parameters and lipid profile}

Blood samples were collected in heparinized tubes and the blood plasma was obtained by centrifugation at 1000 rotations per minute (rpm) for 15 minutes. The lipid profiles, Alanine aminotransferase (ALT) and Aspartate aminotransferase (AST) were evaluated using the Randox ${ }^{\circledR}$ kits.

\section{Statistical Analysis}

Data were analysed by using GraphPad Prism software version 7 and were presented as mean \pm standard error of mean (SEM). Statistical analysis of data was carried out using one-way and two-way Analysis of Variance (ANOVA), followed by Dunnet's test for comparison between groups. $p$ values less than 0.05 ( $p<0.05$ ) were regarded as statistically significant.

\section{RESULT and DISCUSSION}

Obesity is a chronic disorder characterized by increased concentration of various forms of lipids and increased fat deposition. This is mostly due to an imbalance consumption and expenditure of energy resulting in an increase in the number of adipocytes ${ }^{18}$.

A number of health issues particular reno-cardiovascular among others have been associated with obesity ${ }^{19}$. In recent past, a number of drugs have been designed to correct the imbalance in energy intake and expenditure, but most 
of these drugs despite their efficacy have limited clinical use because of the severity of their side effects and exorbitant cost ${ }^{20}$. Thus, this study investigated the anti-obesity activity and probable mechanism of Irvingia gabonensis seed extract by evaluating its effect on lipid profile and biochemical parameters.

The decreased deposition of fat in the visceral region i.e. perianal and perirenal indicates antiobesity activity of compounds ${ }^{21}$. I. gabonensis $(50-200 \mathrm{mg} / \mathrm{kg})$ decreased the body mass index and abdominal fat deposition in high fat dietinduced obese rats.

High fat diet induces obesity by significantly increasing the intake of energy and causing a magnified imbalance in energy expenditure. One of pharmacological approach to treatment of obesity is by blocking fat uptake, and newer approaches have focused on control of energy balance ${ }^{22}$. High fat diet induce obesity by increasing level of total cholesterol, triglyceride, and LDL in serum, demonstrating development of hyperlipidemia.

Irvingia gabonensis seed fiber might bind to bile acids in the gut and transport them out of the body through faeces. This might induce the body to convert more cholesterol into bile acids hence reducing cholesterol levels ${ }^{23}$.

Irvingia gabonensis seed extract significantly reduced cholesterol (at 50 and $100 \mathrm{mg} / \mathrm{kg} ; 69.6,73.2$ vs. 77.2 ), triglyceride (at $50 \mathrm{mg} / \mathrm{kg} ; 54.6$ vs. 58.8 ), and LDL (at 50, 100 and $200 \mathrm{mg} / \mathrm{kg} ; 21.0,20.8,21.0$ vs. 25.2) compared to HFD group. The result suggests that I. gabonensis might possess compounds or active principles which might be useful in preventing the adverse drug effect associated hyperlipidemia. Orlistat, the standard anti-obesity drug used in the study is a pancreatic lipase inhibitor which suppress food intake (hyperphagia) via inhibiting re-uptake of 5 -Hydroxytryptamine $(5 \mathrm{HT})$ at hypothalamic site in the central nervous which regulates appetite ${ }^{24}$. Although the interaction of $I$. gabonensis with monoaminergic transmitters and its endocrine effect particularly on ghrelin were not established in the study, further works still remain to be done in this regard.

The BMI of the rats fed with high fat diets range between $311.6 \pm 2.2$ and $329.8 \pm 2.3$ calculated as Lee's index. The administration of IBG $(50,100,200 \mathrm{mg} / \mathrm{kg})$ and orlistat $(200 \mathrm{mg} / \mathrm{kg})$ significantly $[\mathrm{F}(5,24)=19.73 ; \mathrm{p}<0.0001]$ reduced the BMI of treated rats $(287.6 \pm 4.4,297.6 \pm 2.4,300.2 \pm 3.5$ and $288.7 \pm 3.6$ vs $324.4 \pm 5.4)$ after twelve days of treatment when compared with HFD (Figure 1). 


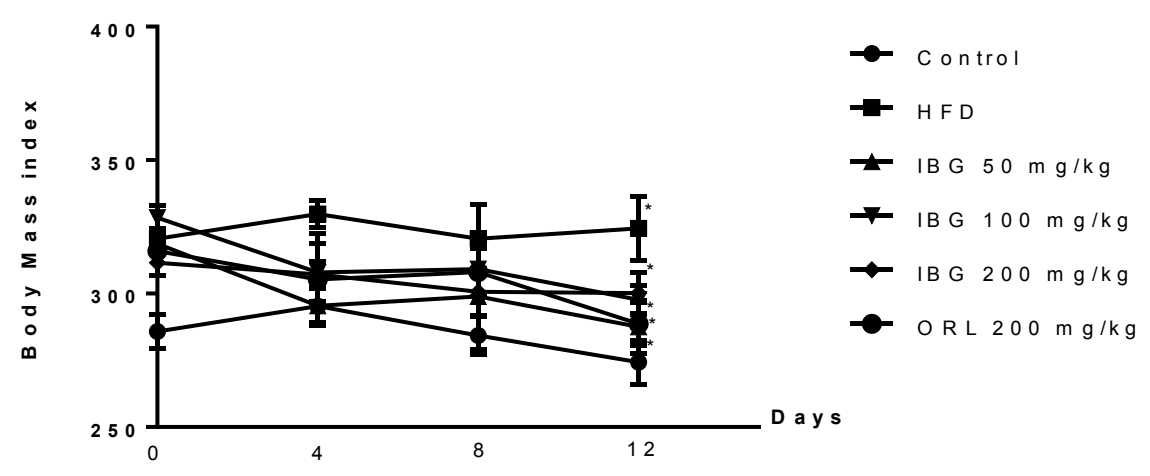

Figure 1: Effect of Ethanol Extract Irvingia gabonensis (IBG) on Body Mass Index (BMI)

All values are expressed mean \pm SEM. Data were analyzed using two way ANOVA for multiple comparison and Dunnett's post-hoc test. * = significant at $\mathrm{p}<0.05$ in comparison with the group of rats fed with HFD.

Body mass index (BMI) of the rats decreased over time during treatment with I. gabonensis, thereby establishing that the plant is beneficial in management of obesity. This was observed from the decreasing Lee's index values from the result as BMI is directly proportional to Lee's index ${ }^{25}$. The measurement of Lee's index is to determine obesity level in the rodent models. This agrees with a similar study carried out which revealed that I. gabonensis plant possess hypolipidemic effect ${ }^{26}$.

The anti-obesity activities of I. gabonensis extract might be due to synergistic actions of secondary metabolites present. The presence of alkaloids, flavonoids, saponins, tannins and phenols has been reported to contribute to anti-obesity effects ${ }^{27}$. Flavonoids act by activating $\beta$-adrenergic receptors involved in the burning of fats by exhibiting PPAR- $\gamma$ ligand binding activity, similar to PPAR- $\gamma$ agonists ${ }^{28}$. Similarly, flavonoids and phenols have also been reported to function as antioxidants, thus preventing obesity by modulating oxidative stresses in the body ${ }^{29}$. In many other studies, alkaloids present in plant extracts significantly reduce the expression levels of several adipocyte marker genes including enhancer binding proteins and proliferator activated receptor hence inhibiting adipogenesis ${ }^{30}$.

The administration of IBG (200 $\mathrm{mg} / \mathrm{kg}$ ) and orlistat $(200 \mathrm{mg} / \mathrm{kg})$ significantly $[\mathrm{F}(5,24)=39.57 ; \mathrm{p}<0.0001]$ reduced the abdominal fat of the animals ( $5.8 \pm 0.4,3.4 \pm 0.1$ vs $6.8 \pm 0.2)$ when compared with the group fed with HFD. At 50 and $100 \mathrm{mg} / \mathrm{kg}$, IBG did not significantly reduce the abdominal fat. 


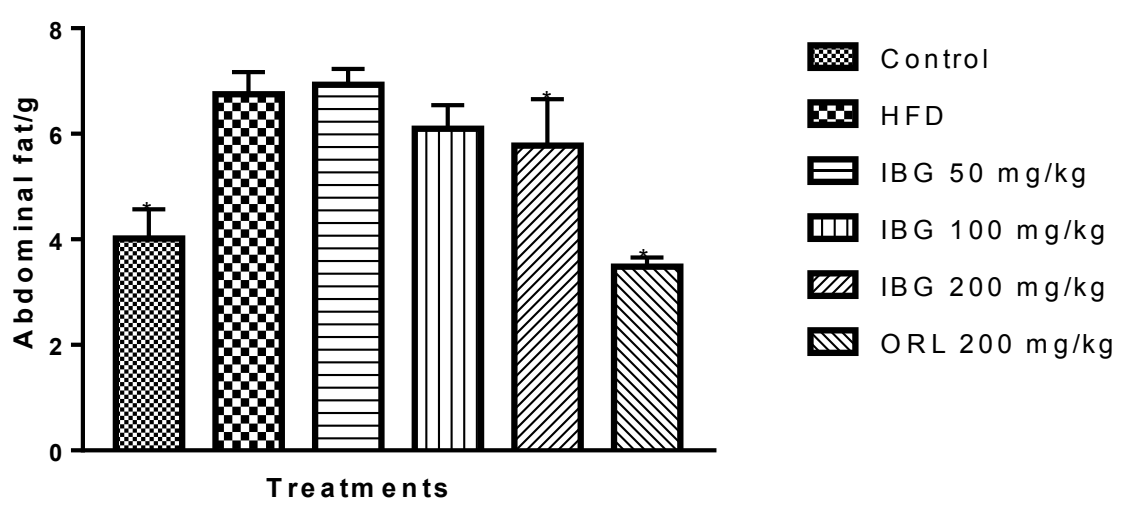

Figure 2: Effect of IBG on abdominal fat

All values are expressed mean \pm SEM. Data were analyzed using one way ANOVA for multiple comparison and Dunnett's post-hoc test. * significant at $\mathrm{p}<0.05$ in comparison with the group of rats fed with HFD.

The doses of IBG used in the study did not significantly reduce the level of cholesterol in the serum. The orlistat $(200 \mathrm{mg} / \mathrm{kg}$ ) did not significantly reduce cholesterol in serum (Figure 3).

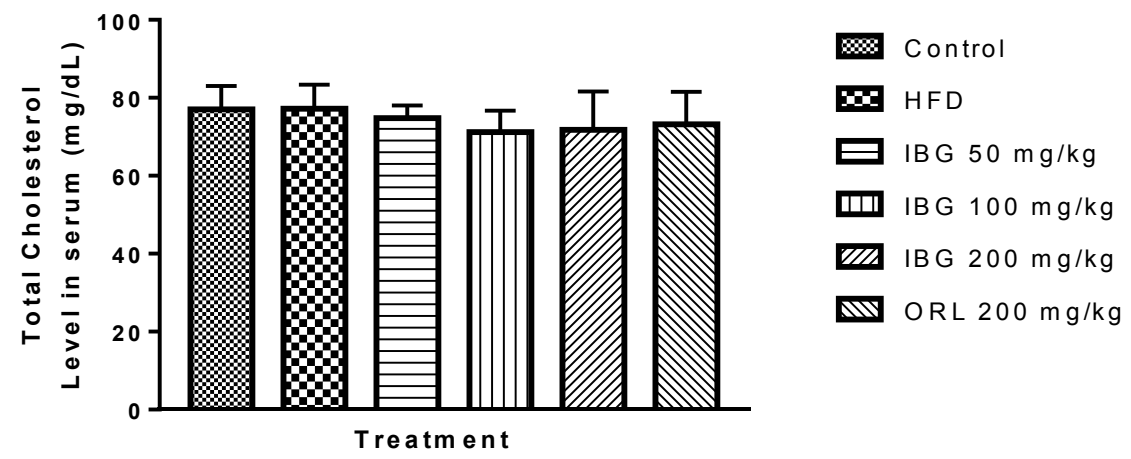

Figure 3: Effect of IBG on total cholesterol in serum

All values are expressed mean \pm SEM. Data were analyzed using one way ANOVA for multiple comparison and Dunnett's post-hoc test.

* = significant at $\mathrm{p}<0.05$ in comparison with the group of rats fed with HFD.

The doses of IBG used in the study did not significantly reduce the level of triglyceride in the serum. The orlistat $(200 \mathrm{mg} / \mathrm{kg}$ ) did not significantly reduce triglyceride in serum (Figure 4). 


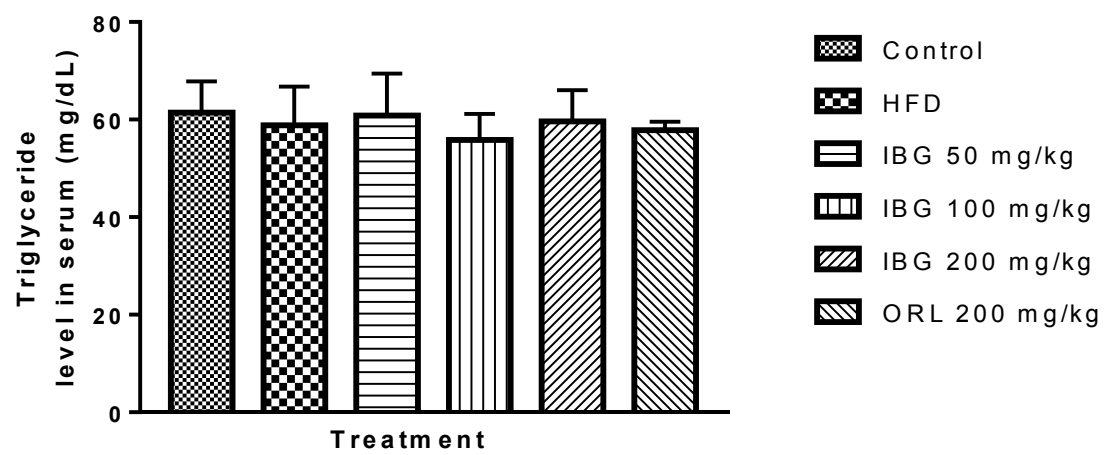

Figure 4: Effect of IBG on triglyceride in serum

All values are expressed mean \pm SEM. Data were analyzed using one way ANOVA for multiple comparison and Dunnett's post-hoc test.

${ }^{*}=$ significant at $\mathrm{p}<0.05$ in comparison with the group of rats fed with HFD.

The doses of IBG used in the study did not significantly reduce the level of HDL in the serum. Orlistat $(200 \mathrm{mg} / \mathrm{kg}$ ) did not also significantly reduce HDL in serum (Figure 5).

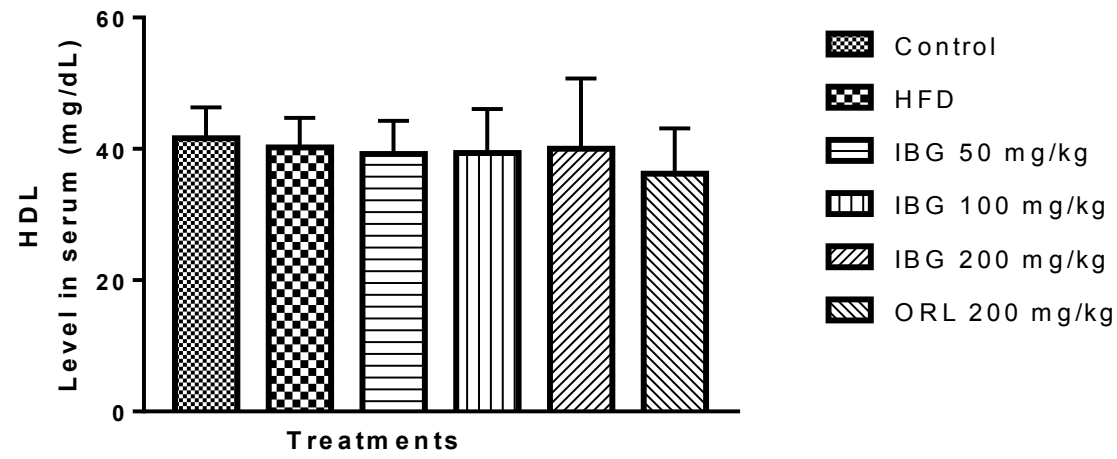

Figure 5: Effect of IBG on High Density Lipoproteins (HDL) in serum

All values are expressed mean \pm SEM. Data were analyzed using one way ANOVA for multiple comparison and Dunnett's post-hoc test.

* = significant at $\mathrm{p}<0.05$ in comparison with the group of rats fed with HFD.

The administration of IBG (200 $\mathrm{mg} / \mathrm{kg}$ ) significantly reduced the level of low density lipoproteins (LDL) in the serum. Orlistat $(200 \mathrm{mg} / \mathrm{kg}$ ) did not significantly reduce LDL in serum (Figure 6). 


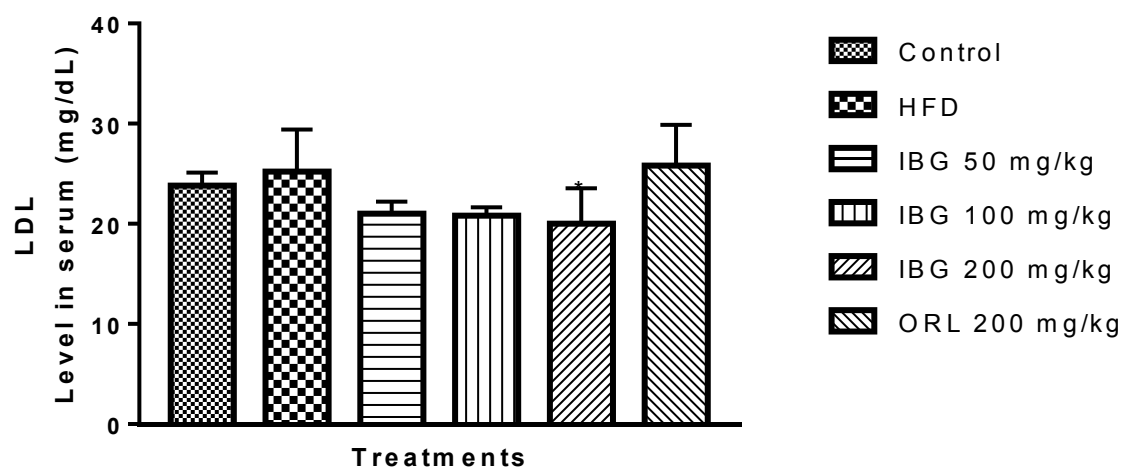

Figure 6: Effect of IBG on Low density lipoprotein (LDL) in serum

All values are expressed mean \pm SEM. Data were analyzed using one way ANOVA for multiple comparison and Dunnett's post-hoc test. ${ }^{*} \mathrm{p}<0.05$ in comparison with the group of rats fed with HFD.

The administration of IBG did not significantly reduce the level of Very low density lipoproteins (VLDL) in the serum. Orlistat (200 mg/kg) did not significantly reduce VLDL in serum (Figure 7).

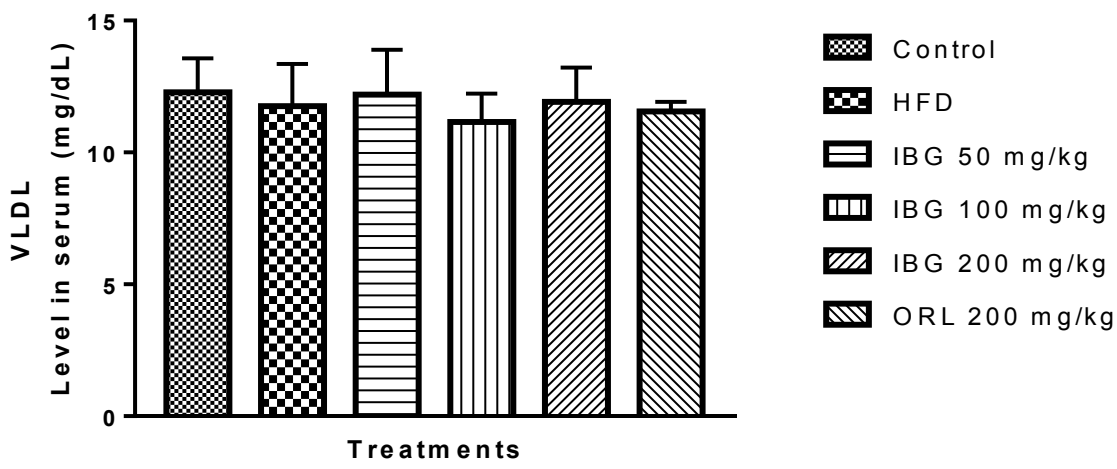

Figure 7: Effect of IBG on VLDL in serum

All values are expressed mean \pm SEM. Data were analyzed using one way ANOVA for multiple comparison and Dunnett's post-hoc test.

It is known that plasma AST and ALT levels are the most reliable laboratory indicators of hepatotoxic effects ${ }^{31}$. The normal ALT level for rats is between 10 to 40 units per liter (U/L) and that of AST for rats is 50 to150 U/L ${ }^{32}$. The ALT, AST, and creatinine levels in serum of animals treated with I. gabonensis, 
revealed no detectable adverse toxic effects as they were comparable to levels in reference Orlistat treated animals. The ALT values for the rats treated with IBG $50-200 \mathrm{mg} / \mathrm{kg}$ ranged from $26-28 \mathrm{U} / \mathrm{L}$ and the ALT value of the rats treated with orlistat $200 \mathrm{mg} / \mathrm{kg}$ was $27 \mathrm{U} / \mathrm{L}$. The ALT value for the HFD control group was $26 \mathrm{U} / \mathrm{L}$. Also, the AST values of the rats treated with IBG $50-200 \mathrm{mg} / \mathrm{kg}$ ranged from 38-39 U/L and the AST value of the rats treated with Orlistat was $37 \mathrm{U} / \mathrm{L}$. The AST value for the HFD control group is $38 \mathrm{U} / \mathrm{L}$. This shows that the ALT values were normal for all the treated rats and the AST values were below the normal range. Also, there was no increase in AST and ALT levels of EIGS treated rats compared to the HFD control group. Hence, the usage of EIGS is shown to be safe as it has no hepatotoxic effect with short term use. Creatinine level is used to check the kidney function. Normal creatinine levels in rats range from 0.5 to $2.2 \mathrm{mg} / \mathrm{dL}$. The creatinine values for animals treated with EIGS ranged from $0.52-0.56 \mathrm{mg} / \mathrm{dL}$ vs $0.56 \mathrm{mg} / \mathrm{dL}$ for the HFD control group. Hence, EIGS is shown to have no toxic effect on the kidney.

The doses of IBG used in the study did not significantly increase the level of glucose in the serum. Also the orlistat $(200 \mathrm{mg} / \mathrm{kg}$ ) did not significantly increase glucose level in serum (Figure 8).

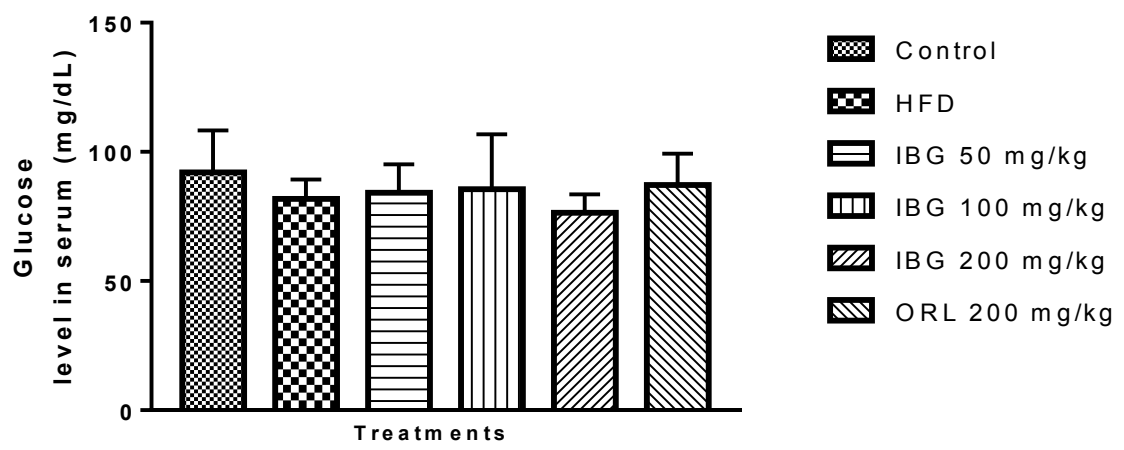

Figure 8: Effect of IBG on glucose in serum

All values are expressed mean \pm SEM. Data were analyzed using one way ANOVA for multiple comparison and Dunnett's post-hoc test.

Also, Irvingia gabonensis seeds might delay stomach emptying which leading to a more gradual absorption of dietary sugar and this effect reduces the raise in blood glucose that is typical after a meal ${ }^{23}$. EIGS at 50,100 and $200 \mathrm{mg} / \mathrm{kg}$ revealed no significant change in the glucose level of the rats compared to the HFD group. 
The doses of IBG used in the study did not significantly increase the level of ALT and AST in the serum. Also the orlistat $(200 \mathrm{mg} / \mathrm{kg}$ ) did not significantly increase ALT and AST in serum (Figure 9).

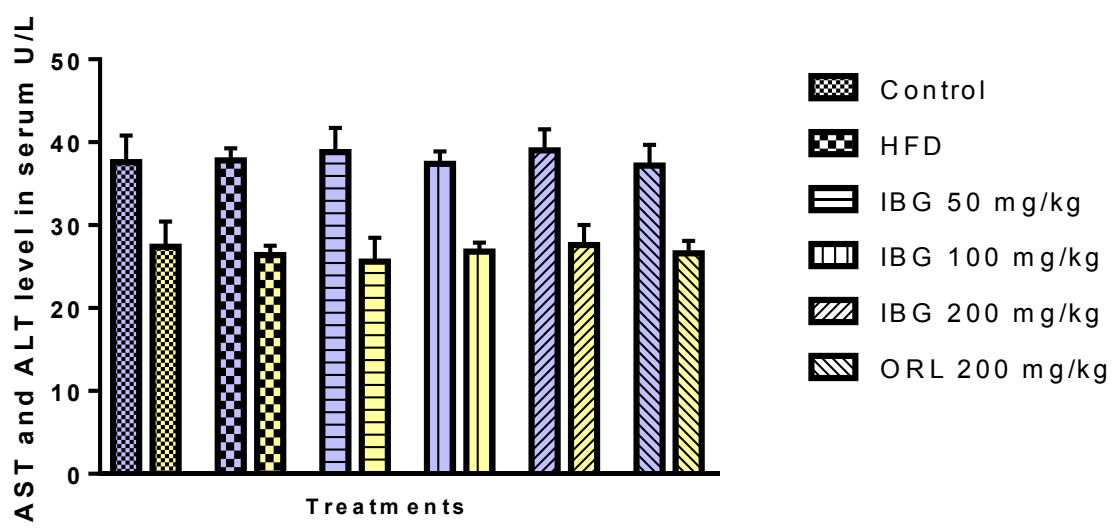

Figure 9: Effect of IBG on AST and ALT in serum

All values are expressed mean \pm SEM. Data were analyzed using one way ANOVA for multiple comparison and Dunnett's post-hoc test.

AST = Aspartate aminotransferase (blue bar)

ALT = Alanine aminotransferase (yellow bar)

The doses of IBG used in the study did not significantly increase the level of creatinine in the serum. Also the orlistat (200 $\mathrm{mg} / \mathrm{kg}$ ) did not significantly increase creatinine level in serum (Figure 10).

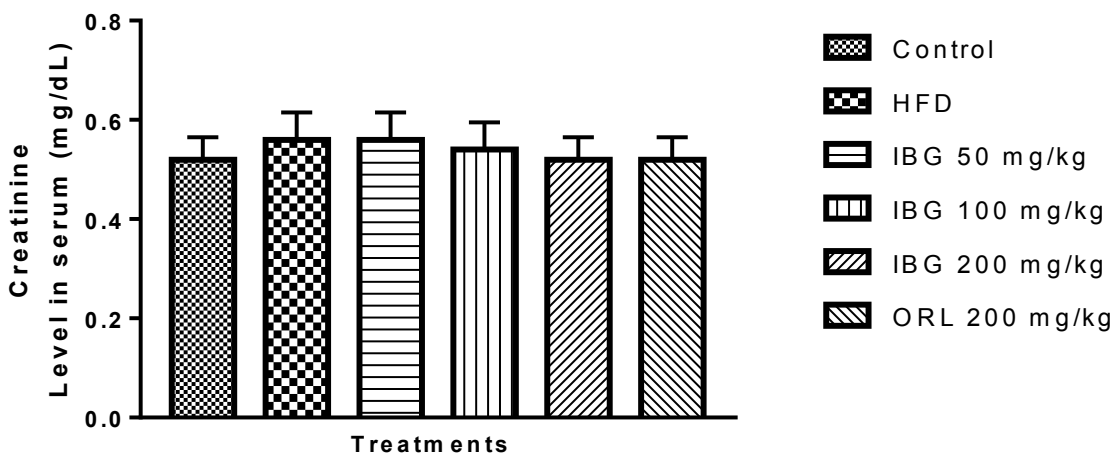

Figure 10: Effect of IBG on creatinine in serum 
All values are expressed mean \pm SEM. Data were analyzed using one-way ANOVA for multiple comparison and Dunnett's post-hoc test.

In the present study, there was no toxicity outcome in both the Orlistat and IBG treated rats. No significant difference ( $>>0.05$ ) was observed in the serum levels of HDL, Triglyceride, total cholesterol and LDL in both the Orlistat and IBG extract treated groups. However, there was a significant decrease in IBG treated rats at $200 \mathrm{mg} / \mathrm{kg}$ in the LDL serum level when compared to the orlistat treated rats. There was also a significant reduction in abnormal fat $(\mathrm{g})$ in groups treated with Orlistat at $200 \mathrm{mg} / \mathrm{kg}$ and IBG treated animals $(200 \mathrm{mg} /$ $\mathrm{kg}$ ) which could be as a result of dose dependent pattern respectively. In the serum glucose levels of all the experimental animals, there were no significant changes among the Orlistat and IBG treated animals respectively as observed in the present study. There was also no significant changes in the Serum levels of liver enzymes and creatinine of Orlistat treated rats in comparison with the IBG treated groups as obtained. This reveals that the ethanol extract of Irvingia gabonensis seeds might possess comparable anti-obesity effects by decreasing the BMI and weight of abdominal fat via reduction of the plasma levels of total cholesterol, triglyceride and LDL in treated animals and could therefore, serve as templates for anti-obesity drug development. 


\section{REFERENCES}

1. Gupta D, Bhardwaj R, Gupta RK. In vitro antioxidant activity of extracts from the leaves of Abies pindrow Royle. Afr J Tradit Complement Altern Med. 2011; 8(4):391-7. https://doi. org/10.4314/ajtcam.v8i4.8 PMID: 22654216.

2. Overweight and obesity. Division of Nutrition, Physical Activity, and Obesity, National Center for Chronic Disease Prevention and Health Promotion June 2020.

3. Mahnaz K, Che WJ, Geoffrey AC, Iman Y. Potential of Traditional Medicinal Plants for Obesity: A review. 2012 International Conference on Nutrition and Food Sciences IPCBEE 2012, 39, IACSIT Press, Singapore.

4. Yun JW. Possible anti-obesity therapeutics from nature-a review. Phytochemistry. 2010 Oct; 71(14-15):1625-41. https://doi.org/10.1016/j.phytochem.2010.07.011 PMID: 20732701.

5. Kiess W, Petzold S, Töpfer M, Garten A, Blüher S, Kapellen T, et al. Adipocytes and adipose tissue. Best Pract Res Clin Endocrinol Metab. 2008; 22(1):135-53. https://doi.org/10.1016/j. beem.2007.10.002 PMID: 18279785 .

6. Roberts CK, Berger JJ, Barnard RJ. Long-term effects of diet on leptin, energy intake, and activity in a model of diet-induced obesity. J Appl Physiol. 2002; 93(3):887-93. https://doi. org/10.1152/japplphysiol.00224.2002 PMID: 12183482

7. Frederich RC, Hamann A, Anderson S, Löllmann B, Lowell BB, Flier JS. Leptin levels reflect body lipid content in mice: evidence for diet-induced resistance to leptin action. Nat Med. 1995; 1(12):1311-4. https://doi.org/10.1038/nm1295-1311 PMID: 7489415

8. Ichihara S, Yamada Y. Genetic factors for human obesity. Cell Mol Life Sci. 2oo8; 65(78):1086-98. https://doi.org/10.1007/sooo18-007-7453-8 PMID: 18097636

9. Vojtech H. Comparative Efficacy and Safety of Pharmacological Approaches to the Management of Obesity. Diabetes Care. 2011; 34(2):349-54.

10. Kumar P, Bhandari U. Common medicinal plants with antiobesity potential: A special emphasis on fenugreek. Anc Sci Life. 2015; 35(1):58-63. https://doi.org/10.4103/02577941.165629 PMID: 26600669

11. Patra S, Nithya S, Srinithya B, Meenakshi SM. Review of Medicinal Plants for Anti-Obesity Activity. Transl Biomed. 2015; 6(3):3. https://doi.org/10.21767/2172-0479.100021.

12. Tobe H, Raven PH. Embryology of the Irvingiaceae, a family with uncertain relationships among the Malpighiales. J Plant Res. 2011; 124(5):577-91. https://doi.org/10.1007/s10265010-0393-7 PMID: 21116833

13. Oyedele T. A and Fatoki, A. Nutritional Composition of Irvingia gabonensis mycoflora with Extracts of Selected Allium Spices. Sci. Eng. Perspectives. 2o17; 12:9-16.

14. Orwa C, Mutua A, Kindt R, Jamnadass R, Anthony S. Agroforestree Database: A free reference and selective guide version 4.0 2009, 1-5 Assessed online 6 June 2017 (http://www. worldagroforestry.org/sites/free/feedatabases.asp)

15. Abalude FO, Ogunkoya MO, Akinjagunla YS. Phytochemical Screening of Leaves and Stem of Cashew Tree Anacardium Occidentale. Electr J. Environ. Agric. Food Chem. 2010; 9:815-9.

16. Onimawo I, Oteno F, Orokpo G, Akuber PI. Physiochemical and Nutrient Evaluation of African Bush Mango (Irvingia gabonensis) seeds and Pulp. Plant Foods Hum Nutr. 2oo3; $58: 1-6$.

17. Obianime AW, Uche FI. Effects of Aqueous Extracts of Irvingia gabonensis Seed on the Hormonal Parameters of Male Guinea Pigs. Asian Pac J Trop Med. 2010; 12:200-4. 
18. Adnyana IK, Elin YS, Yuniarto A, Finna S. Anti-obesity Effects of Pomegramate Leaves Ethanol Extract (Punica granatumi) in High Fat Diet Induced Mice. Int J Pharm Pharm Sci. 2014; 6:626-31.

19. Cercato C, Fonseca FA. Cardiovascular risk and obesity. Diabetol Metab Syndr. 2o19; 11(1):74. https://doi.org/10.1186/s13098-019-0468-o PMID:31467596

20. Van Gaal L, Dirinck E. Pharmacological Approaches in the Treatment and Maintenance of Weight Loss. Diabetes Care. 2016; 39 Suppl 2:S260-7. https://doi.org/10.2337/dcS15-3016 PMID:27440841

21. Yuniarto A, Sukandar EY, Fidrianny I, Crystalia AA, Adnyana IK. Zebra Fish Model of Obesity: Relevance to Metabolic Syndrome. Int. J. Green Pharm. 2019; 13:175-9.

22. Kim Y, Lee H, Kim YK, Park S, Kim J, Yun JH, et al., Association of Metabolites with Obesity and Type 2 Diabetes Based on FTO Genotype. PLoS ONE, 2016; 11:29. e0156612.

23. Ngondi JL, Oben JE, Minka SR. The effect of Irvingia gabonensis seeds on body weight and blood lipids of obese subjects in Cameroon. Lipids Health Dis. 2005; 4(1):12. https://doi. org/10.1186/1476-511X-4-12 PMID: 15916709

24. Kim GW, Lin JE, Blomain ES, Waldman SA. Antiobesity pharmacotherapy: new drugs and emerging targets. Clin Pharmacol Ther. 2o14; 95(1):53-66. https://doi.org/10.1038/ clpt.2013.204 PMID: 24105257

25. Lee CM, Huxley RR, Wildman RP, Woodward M. Indices of abdominal obesity are better discriminators of cardiovascular risk factors than BMI: a meta-analysis. J Clin Epidemiol. 2008; 61(7):646-53. https://doi.org/10.1016/j.jclinepi.2007.08.012 PMID: 18359190

26. Kuyooro SE, Abam EO, Agbede EB. Hypolipidemic Effects of Irvingia gabonensis-Supplemented Diets in Male Albino Rats. Biochem Anal Biochem. 2017; 6(2):21-5. https://doi. org/10.4172/2161-1009.1000316.

27. Nderitu KW, Mwenda NS, Macharia NJ, Barasa SS, Ngugi MP. Antiobesity activities of methanolic extracts of Amaranthus dubius, Cucurbita pepo, and Vigna unguiculata in progesterone-induced obese Mice. Evid Based Complement Alternat Med. 2017; 2017:4317321. https://doi.org/10.1155/2017/4317321 PMID: 28947909

28. Tyagi S, Gupta P, Saini AS, Kaushal C, Sharma S, Kaushal C, et al. The peroxisome proliferator-activated receptor: A family of nuclear receptors role in various diseases. J Adv Pharm Technol Res. 2011; 2(4):236-40. https://doi.org/10.4103/2231-4040.90879 PMID: 22247890

29. Kumar S, Pandey AK. Chemistry and biological activities of flavonoids: an overview. Scientific World Journal. 2013; 2013:162750. https://doi.org/10.1155/2013/162750 PMID: 24470791

30. Chang E, Kim CY. Natural products and obesity: a focus on the regulation of mitotic clonal expansion during adipogenesis. Molecules. 2019; 24(6):1157. https://doi.org/10.339o/molecules24061157 PMID: 30909556

31. Amacher DE. Serum transaminase elevations as indicators of hepatic injury following the administration of drugs. Regul Toxicol Pharmacol. 1998; 27(2):119-30. https://doi. org/10.1006/rtph.1998.1201 PMID: 9671567

32. Agahi A, Murphy KG. Models and strategies in the development of antiobesity drugs. Vet Pathol. 2014; 51(3):695-706. https://doi.org/10.1177/0300985813492801 PMID: 23860008 . 